\title{
INCLINODEFORMOMETER FOR EARTH PRESSURE MEASUREMENTS IN CREEPING LANDSLIDES
}

\author{
Markus V. Schwager ${ }^{\mathrm{i})}$, Andreas M. Schmid ${ }^{\mathrm{ii})}$ and AleXander M. Puzrin ${ }^{\mathrm{iii}}$
}

\begin{abstract}
The inclinodeformometer (IDM) is a novel device for measuring changes in earth pressure in a sliding layer of a creeping landslide. The device makes use of existing and widely used inclinometer measurement technology. The change of earth pressure in the sliding layer leads to changes in the shape and dimensions of the incinometer pipe. Careful measurements of these changes make it possible to backcalculate the pressure increment from the solution of a boundary value problem with properly described constitutive behaviors of the pipe and surrounding soil. An advantage of the inclinodeformometer is that it does not require any additional infrastructure than standard inclinometer pipes, even long after they are sheared and became unsuitable for inclinometer measurements. Full scale laboratory tests performed in a $2 \mathrm{~m}$ high calibration chamber demonstrated that simple constitutive models can be used for backcalculation as a first approximation. Initial field measurements performed on the St. Moritz landslide confirmed the existence of a compression zone in this constrained creeping landslide, and gave an order of magnitude for the pressure increment. This confirms the shear strength on the sliding surface decreased over time, implying that Brattas landslide in St. Moritz has to be analyzed considering a "potential failure scenario".
\end{abstract}

Key words: creeping landslide, earth pressure, inclinometer, inverse analysis, mitigation measurements (IGC: $\mathrm{B} 3 / \mathrm{C} 3 / \mathrm{E} 5)$

\section{INTRODUCTION}

Information about the earth pressure changes in sliding layers of a creeping landslide is essential for understanding, analyzing and stabilizing the creeping landslides. The combination of displacement and pressure change measurements in two sections of a long thin sliding layer (Fig. 1) allows for a backcalculation of the average shear strength on the sliding surface and average lateral stiffness of the soil in the sliding layer.

Of even greater importance, however, is information about the earth pressure changes for constrained landslides, where the pressures in the compression zone have the potential to reach the passive pressure and lead to a catastrophic failure (Puzrin and Sterba, 2006). Our investigation was focussed on the Brattas landslide of St. Moritz in Switzerland (a detailed geological and geotechnical description of the landslide is presented in Schluechter, 1988; Sterba et al., 2000). The rock outcrop at the bottom of the sliding layer along the Via Maistra, shown in Fig. 2, which can be clearly identified from the contours of yearly horizontal displacements, sets this landslide apart from others. The long-term stability of the Brattas landslide is of great concern for the St. Moritz community.

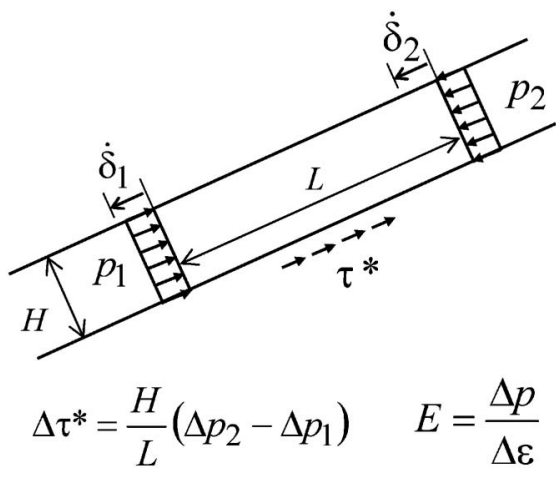

Fig. 1. Backcalculation of the average shear strength on the sliding surface and average lateral stiffness of soil

Our long tern stability analysis of this constrained landslide was based on the considerations set out by Puzrin and Sterba in 2006. In terms of the development in time of the shear strength on the sliding surface (Fig. 3), we distinguished between two possible scenarios: the "safe scenario", where the shear strength stays constant, and the "potential failure scenario", where the shear strength decreases over time. This drop in shear strength can be attributed to several factors explained as follows:

i) Research Assistant, Institute for Geotechnical Engineering, Switzerland (markus.schwager@igt.baug.ethz.ch).

ii) ditto.

iii) Professor, Institute for Geotechnical Engineering, Switzerland.

The manuscript for this paper was received for review on August 24, 2009; approved on January 21, 2010.

Written discussions on this paper should be submitted before March 1, 2011 to the Japanese Geotechnical Society, 4-38-2, Sengoku, Bunkyo-

$\mathrm{ku}$, Tokyo 112-0011, Japan. Upon request the closing date may be extended one month. 
- The decrease of the shear strength towards the residual strength is due to the continuing displacement of the sliding layer.

- The decrease of the rate dependent component of the shear strength drop is due to the observed continuous slowing down of the movement of a constrained landslide.

In order to maintain the equilibrium and compensate for the decrease in the shear strength along the sliding surface in the "potential failure scenario", the pressure at the sliding layer and in particular at the bottom of the landslide should increase (in the "safe scenario" it remains constant). If it doesn't, the earth pressure at the bottom of the landslide will eventually exceed the passive soil resistance, leading to a catastrophic slope failure. Measurements of pressures at the bottom of a constrained landslide are the only direct means to distinguish between the safe and the potential failure scenarios.

Unfortunately, measuring the earth pressure is also one of the most challenging problems in geotechnical monitoring. In this paper, we introduce a novel device called a inclinodeformometer (IDM), which makes it possibl to carry out backcalculations of the changes of earth pressure using a two step procedure. In the first step, the IDM is used to measure the change in dimensions of an inclinometer pipe in the sliding layer. The change in shape is assumed to be caused by the changes in the surrounding stress field. In the second step, the measured deformations are used to backcalculate the change in pressure via

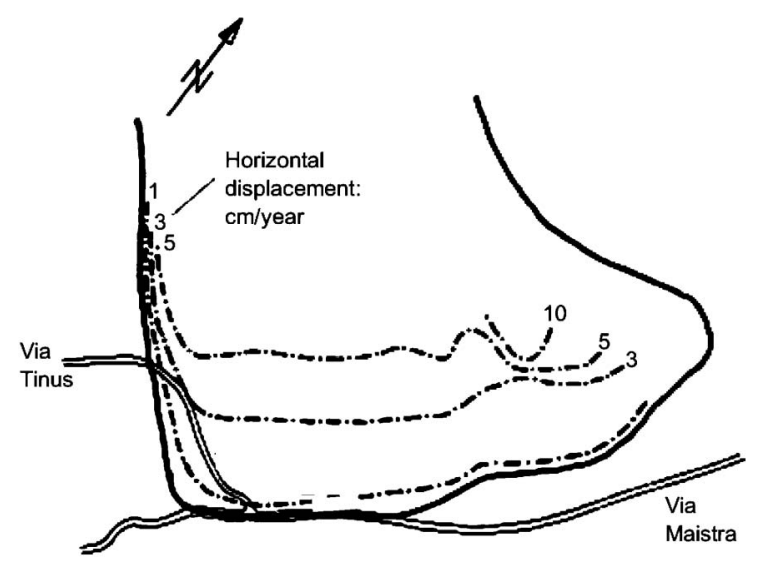

Fig. 2. The Brattas landslide of St. Moritz: The landslide displacements in the lower $200 \mathrm{~m}$, longterm survey until 1982 (after Schluechter, 1988)

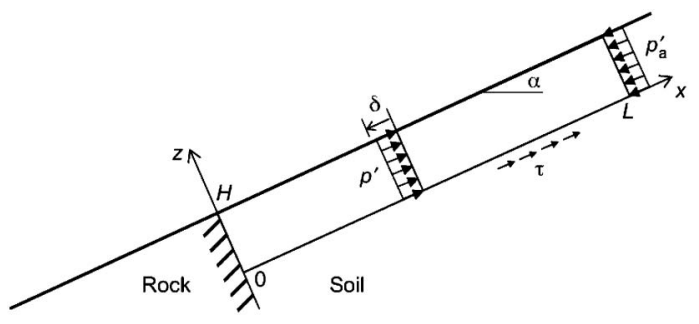

Fig. 3. Schematic layout of constrained landslide model (after Puzrin and Sterba, 2006) an inverse analysis of the corresponding boundary value problem of a plastic pipe surrounded by soil under a changing stress state.

Here we explain the IDM design and the required correction and calibration procedures for the deformation measurements, as well as the procedure for making backcalculations of the pressure changes in the surrounding soil. These procedures are then validated in full scale calibration chamber tests and applied to obtain the initial measurements of the pressure changes at the bottom of the Brattas landslide.

\section{MEASURING THE PIPE DEFORMATIONS}

\section{IDM Design}

The inclinodeformometer (IDM) makes use of the existing and widely used inclinometer measurement technology. An IDM probe is lowered down the depth of a pipe on three wheels and guided along the channels of the inclinometer pipe (Fig. 4). Continuous diameter measurements in two perpendicular directions can be taken based on the following design.

The upper and the lower wheels roll in the same channel. These wheels are fixed to the probe, and the middle wheel is connected via a lever with two springs, so that it can be pressed against the opposite channel. A change in the diameter of the pipe leads to a change in the position of the middle wheel with respect to the probe. There are two tilt sensors detecting the relative inclination between the probe and the lever of the middle wheel. One sensor is located on the top of the probe, and the other one is on the middle wheel (Fig. 4).

In addition to the two tilt sensors along the plane of the measured diameter, there is another tilt sensor to make measurements perpendicular to this plane. This sensor is

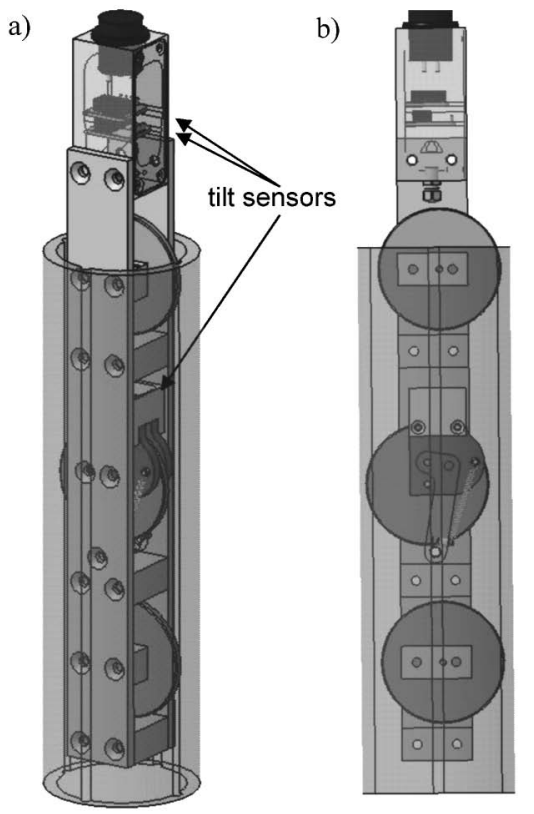

Fig. 4. The inclinodeformometer in the inclinometer pipe: a) the complete device, b) the device without the front panel 
used for the correction of the measurements due to the out-of-plane inclination of the pipe (see Section Correction for the Pipe Out-of-plane Inclination). Above the top wheel there is a pressure cell to measure the water pressure in the inclinometer pipe.

At the top of the borehole, the cable on which the device hangs, goes around a wheel. An incremental rotation sensor measures the wheel rotation, which determines the depth of the device in the inclinometer pipe. As the device is lowered down into the inclinometer pipe, all the sensor measurements with regard to the corresponding depth position in the pipe, are saved on a computer.

The IDM was designed to accommodate the two most common diameters of inclinometer pipes in Switzerland: 71 and $84 \mathrm{~mm}$. The device can be easily switched between different inclinometer pipe diameters.

\section{Correction for the Pipe Out-of-plane Inclination}

The measured diameter $D$ inside the pipe is a function of the two angles $\alpha_{\mathrm{W}}$ and $\alpha_{\mathrm{P}}$ measured at the middle wheel and at the probe:

$$
D=d+X+\sin \left(\alpha_{\mathrm{W}}-\alpha_{\mathrm{P}}\right) \cdot Y
$$

where $X, Y$ and $D$ are constants depending on geometry.

The measurements of $\alpha_{\mathrm{W}}$ and $\alpha_{\mathrm{P}}$ are not independent of the inclination $\beta$ of the device out of the plane. Assuming that the sensors give the true $\left(\alpha_{\mathrm{W}}-\alpha_{\mathrm{P}}\right)$ value at $\beta=0^{\circ}$, an error occurs with the tilt measurements when $\beta$ differs from $0^{\circ}$. Because the diameter is just a function of the difference $\left(\alpha_{\mathrm{W}}-\alpha_{\mathrm{P}}\right)$, it is sufficient to describe the error $\Delta$ affecting this difference. This error can be found by calibrating the measurements on a biaxial inclinable table (Fig. 5).

The error due to the device being inclined out of the

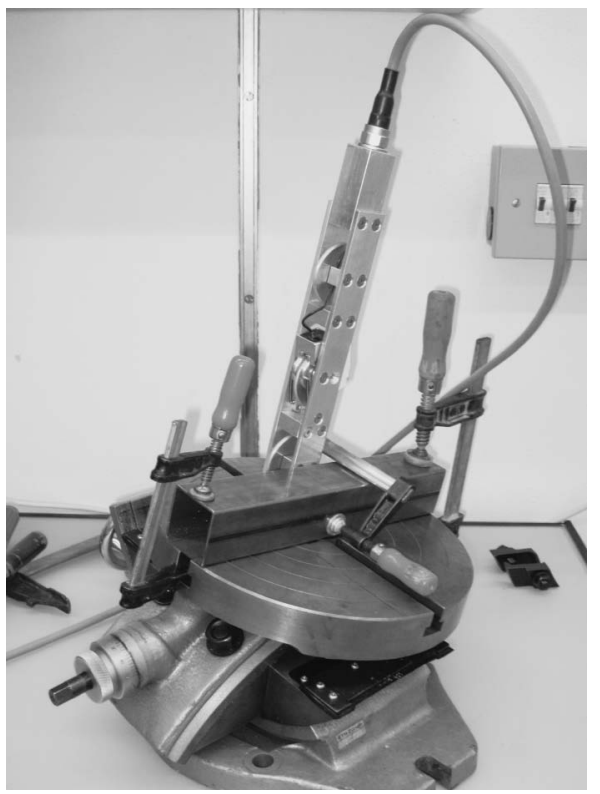

Fig. 5. The inclinodeformometer on a biaxial inclinable table for calibration measurements plane can be described as a function of $\alpha_{\mathrm{W}}, \alpha_{\mathrm{P}}$ and $\beta$ as follows:

$$
\begin{aligned}
\Delta\left(\alpha_{\mathrm{W}}-\alpha_{\mathrm{P}}\right)= & \left(A_{1} \alpha_{\mathrm{W}}+A_{2} \alpha_{\mathrm{P}}+A_{3}\right) \beta^{2} \\
& +\left(C_{1} \alpha_{\mathrm{W}}+C_{2} \alpha_{\mathrm{P}}+C_{3}\right) \beta
\end{aligned}
$$

where $A_{1}, A_{2}, A_{3}, C_{1}, C_{2}$ and $C_{3}$ are constants derived by a regression analysis of the calibration measurements. After correcting the difference $\left(\alpha_{\mathrm{W}}-\alpha_{\mathrm{P}}\right)$ using the error function, the correct diameter $D_{\text {cor }}$ is obtained.

$$
D_{\text {cor }}=d+X+\sin \left(\alpha_{\mathrm{W}}-\alpha_{\mathrm{P}}-\Delta\right) \cdot Y
$$

By using the error function from Eq. (2), the corrected measurements of the diameter $D$ reach the precision of $+/-1.4$ micrometers within $\beta=+/-4^{\circ}$, compared to the measurement at $\beta=0^{\circ}$ (Fig. 6).

\section{Calibration of the Device}

The aim of the IDM is to compile measurements of the

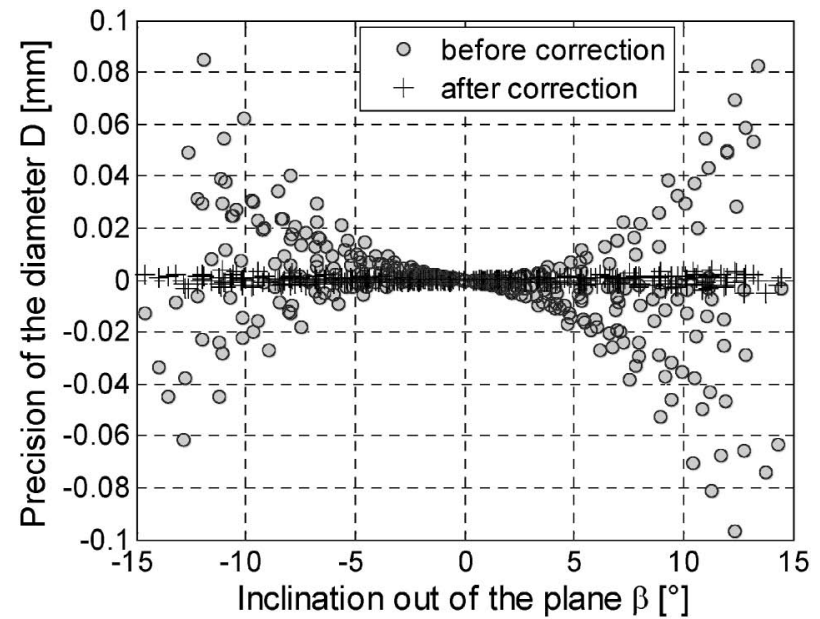

Fig. 6. The precision of the diameter $D$ compared to the measurement at $\beta=0^{\circ}$

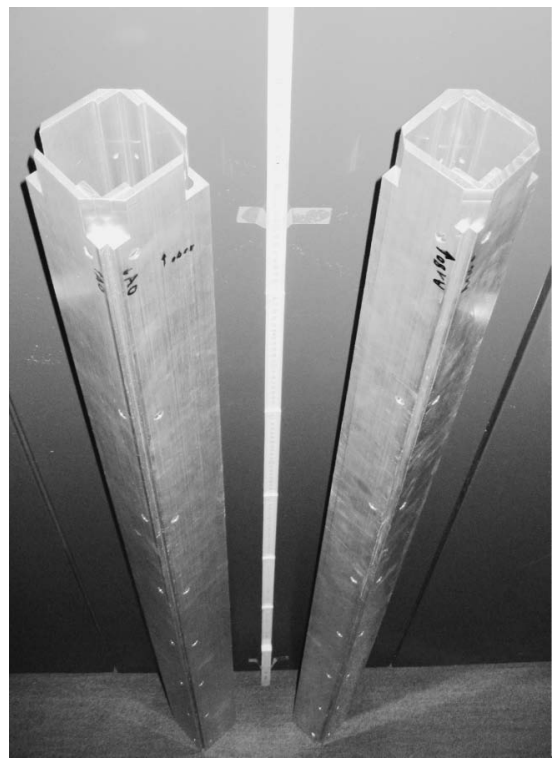

Fig. 7. The reference gauges for both types of inclinometer pipes 
diameters of the inclinometer pipes taken over a period of several years in order to compute the change in shape. It is therefore important to avoid the influence of any shift that takes place in the device reference. For this reason, field measurements taken over different years should be preceded by a calibrations made by a constant diameter high precision reference gauge. There are two different reference gauges for both types of inclinometer pipes (Fig. 7). The precision that can be reached in calibration is within $+/-3$ micrometers. This has a major impact on the precision of inclinodeformometer in terms of the backcalculated pressure increments.

\section{BACKCALCULATING PRESSURES}

\section{Boundary Value Problem}

The pressure changes can be backcalculated from a solution of an inverse plane stress boundary value problem (Fig. 8) using the measured changes in pipe diameters, provided the stiffness of the soil and the stiffness of the pipe in this range of stresses are known. The boundary conditions tend to be static: the two principal earth pressures. The major principal stress direction is assumed to coincide with the direction of the displacement vector, which is indicated by the conventional inclinometer measurements.

Besides the changes in earth pressure, the measured diameters are affected by the the bending of the inclinometer pipe produced by the movement of the landslide. Corrections for these changes have to be carried out before modeling the plain stress problem.

\section{Effects of Stiffness}

The stiffness of the pipe and the soil affect the backcalculation results significantly. Therefore, it is very important to describe the constitutive behavior of the pipe and the surrounding soil in an appropriate way.

\section{Stiffness of the Inclinometer Pipe}

The short term Young's modulus for fast loading of the inclinometer pipe was able be determined by compression tests. The pipe was loaded by a linear distributed

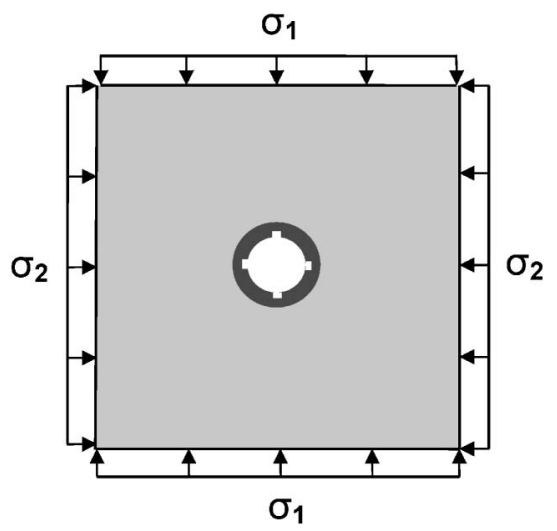

Fig. 8. Plain stress model in case of principle stresses parallel to the axes of the pipe load in a purpose-built test apparatus (Fig. 9). The deformations were measured for several angles between the direction of the force and the direction of the channels in the pipe.

The tangent stiffness of the pipe $k$ is defined as the ratio between the increment of force $f$ divided by the increment of displacement $u$ (or, more precisely, a half of the displacement due to the symmetry of the setup):

$$
k=\frac{\Delta f}{(\Delta u) / 2}
$$

The stiffness is strongly dependent on the angle between the direction of force and also the direction of the channels in the pipe, since they soften the pipe cross-section. The highest stiffness is achieved at the angle of $45^{\circ}$ between the force direction and the channels (Fig. 10). In this configuration, there are hardly any bending moments acting in the area of the channels, where the bending stiffness is reduced significantly.

The Young's modulus $E$ is related to $k$ by an analytical elastic solution for a solid pipe (without channels) loaded by two opposite forces (e.g., Bouma, 1993):

$$
E=\frac{2 k r}{\pi A}+\frac{2 r^{3} k}{\pi I}(1 / 9+1 / 225+1 / 1225+\ldots)
$$

where $r=$ middle radius; $A=$ area of the pipe section; and $I=$ moment of inertia of the pipe section.

Using Eq. (5) with the stiffness $k$ from the $45^{\circ}$ force
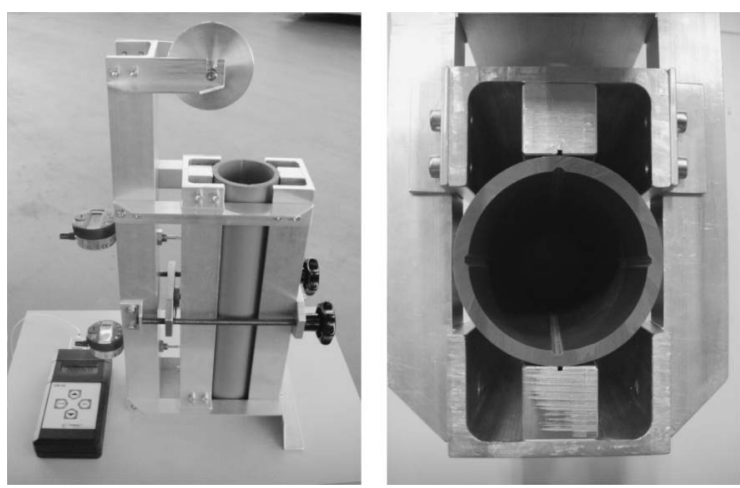

Fig. 9. Compression test on the inclinometer pipe

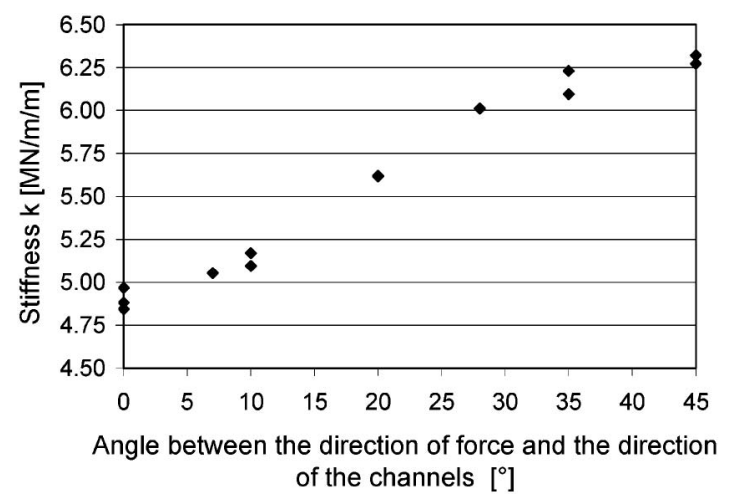

Fig. 10. Stiffness $k$ of the pipe as a function of the direction of force 


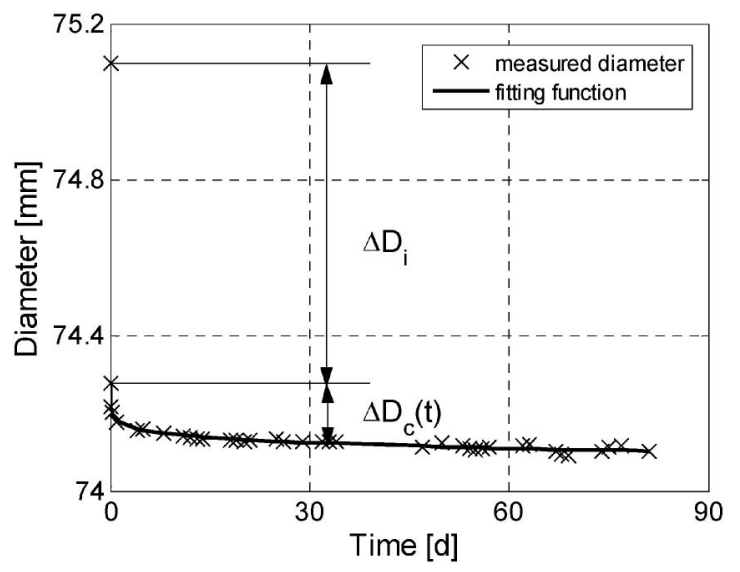

Fig. 11. Results of the creep test in the calibration chamber (constrained boundaries, $\sigma_{1}=125 \mathrm{kPa}$ ) and the fitting function

direction measurement (Fig. 10) leads to an immediate Young' s modulus of $E=2850 \mathrm{MPa}$ for fast loading. In fact, this value can be assumed to be a lower boundary since the formula is made for pipes without channels. Nevertheless, this value was verified by measuring the initial deformation in an element creep compression test.

\section{Creep of the Inclinometer Pipe}

For backcalculations of pressures in creeping landslides, however, the long-term modulus is of much bigger concern than the immediate modulus for fast loading. The viscous behaviour of the pipe has to be considered. Long term creep and relaxation tests are currently being carried out. Figure 11 shows the initial results of the creep test for the first three months: the immediate change in diameter $\Delta D_{\mathrm{i}}$ as well as the time dependent change in diameter $\Delta D_{\mathrm{c}}$ for a constant load of $125 \mathrm{kPa}$ in the calibration chamber with constrained conditions (see Sections Particular Case with Constrained Boundaries and Validation: IDM Box). The total change in diameter is the sum of these two components:

$$
\Delta D(t)=\Delta D_{\mathrm{i}}+\Delta D_{\mathrm{c}}(t)
$$

The following analytical function provided a very good fit to the experimental data for the time dependent change in diameter $\Delta D_{\mathrm{c}}$ :

$$
\Delta D_{\mathrm{c}}(t)=A t^{B}
$$

where $A=-0.15 \mathrm{kPa}$ and $B=2.691 /$ day are constants derived by a regression analysis of the creep measurements.

This extrapolation function can be used to predict the creep component for longer term loading: e.g., the creep over a year period leads to about $25 \%$ increase in pipe deformation compared to immediate loading by the same pressure increment.

\section{Stiffness of the Surrounding Soil}

The stiffness of the surrounding soil can be determined from dilatometer tests performed in the same borehole drilled for the inclinometer. When no field measurements are available, the stiffness of the soil can be roughly estimated from the results of laboratory tests (e.g., consolidation tests). In the case of the St. Moritz landslide, the stiffness was investigated in a field and laboratory program described in detail in Puzrin et al. (2008). Both the loading history and the nonlinearity due to the stress dependency were shown to have a major effect on the soil stiffness; therefore, it is essential to determine the stiffness both in loading and unloading-reloading modes within the expected stress range of the inclinodeformometer measurements.

\section{Stiffness of the Grout Surrounding the Pipe}

In many cases, inclinometer pipes are fixed in boreholes by grouting the annulus using a cement-bentonite mixture. The stiffness of the grout can be estimated from the results of laboratory tests (e.g., consolidation tests). If the stiffness of the grout differs significantly from that of the surrounding soil, the grouted annulus has to be incorporated into the boundary value problem. In practice, however, it is common to use a grout mixture with a stiffness as close as possible to the surrounding soil.

\section{Inverse Analysis}

In general, the soil behavior has to be modeled as viscoelasto-plastic and that of the pipe as visco-elastic with geometric non-linearity due to the channels. Therefore, the forward boundary value problem has to be solved using a numerical analysis. The backcalculation of pressures is performed in two steps: first, a finite element program computes the deformations caused by the trial stresses. An inverse analysis uses a Levenberg-Marquardt algorithm to solve the optimization problem by minimizing the objective function $F$ (the sum of squared errors between the measured and the computed pipe deformations) for the changing trial stresses.

\section{General Case with Static Boundary Conditions}

In most cases, the boundary conditions are given by the two trial principal stresses $\sigma_{1}$ and $\sigma_{2}$. Figure 12 shows the objective function $F$ as a function of $\sigma_{1}$ and $\sigma_{2}$. Both the soil and the pipe are assumed to be elastic, with Young's moduli of the soil and the pipe being set to $50 \mathrm{MPa}$ and $2850 \mathrm{MPa}$, respectively. The Poisson ratios were assumed to be 0.25 and 0.3 , respectively. The minimum of the objective function is located at $\sigma_{1}=100 \mathrm{kPa}$ and $\sigma_{2}=60$ $\mathrm{kPa}$.

The low gradient along the objective function "valley" as seen in Fig. 12 implies that a variety of states of stress may lead to similar pipe deformations. This can be explained in that the bending moments cause much bigger deformations of the pipe than normal forces, and different combinations of the stress ratio $\sigma_{2} / \sigma_{1}$ and the average stress $\left(\sigma_{1}+\sigma_{2}\right) / 2$ can produce the same bending moments at different levels of compression of the pipe. From Fig. 12 , it follows that variation in $\sigma_{2} / \sigma_{1}$ at a fixed $\left(\sigma_{1}+\sigma_{2}\right) / 2$ produces a larger pipe deformation than the other way round. This makes the backcalculation of stress increments more challenging. 


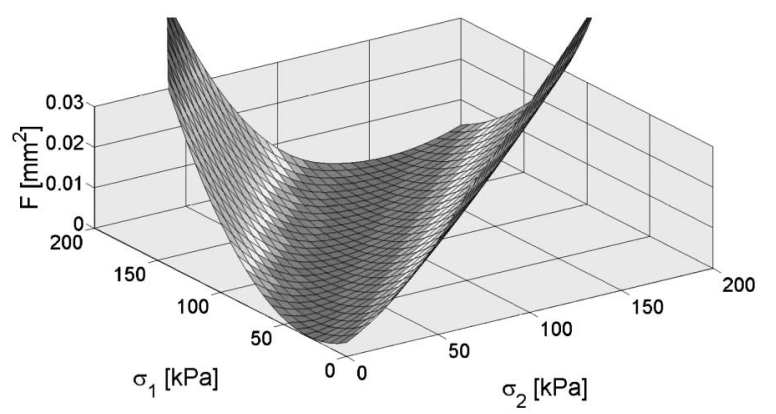

Fig. 12. Objective function for inverse analysis with static boundary conditions

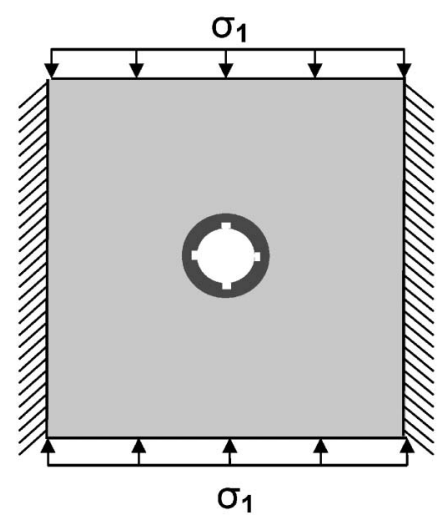

Fig. 13. Plain stress model in case of constrained boundaries in direction of the minor principle stress

Particular Case with Constrained Boundaries

For large creeping landslides with a wide moving front, the plane strain conditions can be assumed in the vertical plane parallel to the slope gradient. This implies that there are no displacements perpendicular to that plane. In this particular case, we can solve a problem with kinematically constrained boundary conditions in the direction of the minor principal stress (Fig. 13). This assumption makes the backcalculation problem well-posed and the solution can be much more easily reached.

Figure 14 shows the objective function $F$ as a function of $\sigma_{1}$ in this particular case for the same constitutive behavior as in Fig. 12. Because the behaviour of both the pipe and the soil is assumed to be elastic, the plot in Fig. 14 is, in principle, a cross-section of the general surface in Fig. 11, given by the plane $\sigma_{2} / \sigma_{1}=v$ (the Poisson ratio of the soil).

Using the results of this inverse analysis, it is possible to backcalculate the minimal resolution of the IDM stress measurements by taking the radial deformation of the pipe equal to the precision of the device $(+/-3$ micrometers, see Section Calibration of the Device). This resolution strongly depends on the model we apply for the backcalculation, especially with regard to the stiffness of the soil and to the boundary conditions. For the conditions used in the above example, the resolution of the device is about $3 \mathrm{kPa}$.

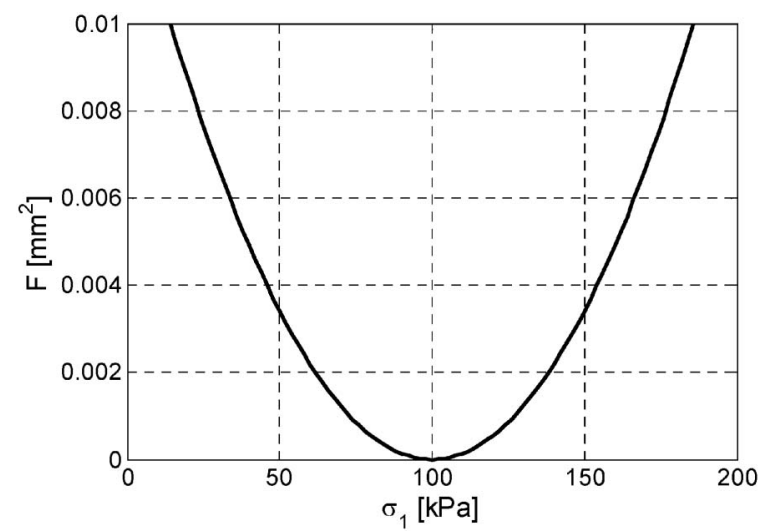

Fig. 14. Objective function for inverse analysis with constrained boundary conditions to the sides
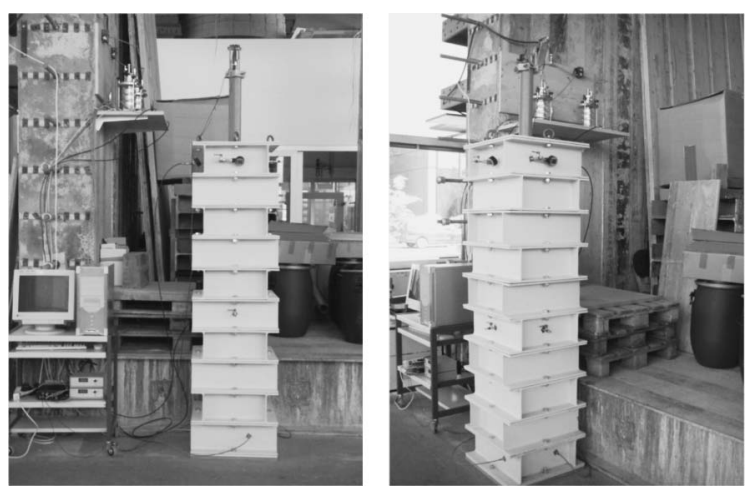

Fig. 15. The IDM box

\section{Validation: IDM Box}

For validation of the backcalculation procedure, full scale laboratory tests were performed in a $2 \mathrm{~m}$ high calibration chamber (IDM-box) with a cross-section of 40 by $40 \mathrm{~cm}$ (Fig. 15). Each of the 4 vertical walls of the chamber is equipped with a pressure membrane allowing for the application of two independent principal horizontal stresses. The chamber is filled with sand and the inclinometer pipe is fixed in the middle of the chamber. Increasing principal stress results in the deformation of the pipe, which is measured using the inclinodeformometer.

Validation using finite elements showed that dimensions of 40 by $40 \mathrm{~cm}$ were sufficient to avoid the effect of the boundaries for the inclinometer pipe with a diameter of $84 \mathrm{~mm}$, when compared with a free field solution.

The boundary conditions applied during the test are shown in Fig. 13. The major principal stress $\sigma_{1}$ was applied via a couple of two opposite pressure membranes. The other two pressure membranes were empty and opened to atmospheric pressure in such a way that the side boundaries experienced zero displacement. The performed stress path contained loading, unloading, reloading and again unloading. For the backcalculation, an elastic modulus of soil $E$ of $7 \mathrm{MPa}$ was used for loading and $51 \mathrm{MPa}$ for reloading. The comparison between applied pressures and pressures backcalculated for both 
pipe diameters is given in Fig. 16. It can be seen that the elastic model can be used for backcalculation and is a reasonable first approximation. Resolution of the pressure measurement (for the same precision of $+/-3$ micrometers, see Section Calibration of the Device) in initial loading is $0.9 \mathrm{kPa}$, while in unloading-reloading it is 3 $\mathrm{kPa}$. As expected, softer soils provide better resolution for pressure measurements.

\section{INITIAL FIELD MEASUREMENTS}

The first field application of the IDM took place at three different locations in the compression zone of the St. Moritz landslide (Fig. 17). Since all three inclinometers were sheared in the sliding surface, all the measurements were taken inside the sliding layer. In the zero measurement taken in November 2008, it was confirmed that the inclinometer pipes were elliptical in shape, with the smaller diameter parallel to the direction of the land-

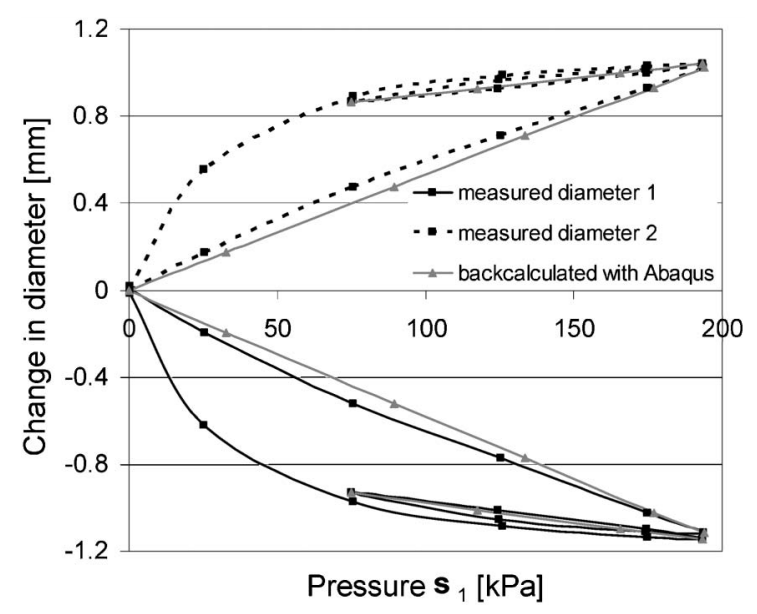

Fig. 16. The comparison between the backcalculated and applied pressures in the IDM box experiments with boundary conditions as shown in Fig. 12 slide movement confirming the existence of the compression zone (Schwager et al., 2009).

The second measurement was taken almost eight months later in July 2009. The pipe diameters were averaged every 3 meters-e.g., within each continuous pipe section between the installation joints. The diameter in direction $\mathrm{A}$, which was close to the direction of displacement, decreased in all the $3 \mathrm{~m}$ sections in all three inclinometer pipes (Fig. 18), which confirms the continuous increase in earth pressure in the compression zone.

For the backcalculation of the earth pressure increments, the change in the pipe diameter A was averaged over the height of the sliding layer. Two different assumptions were explored with respect to the direction of the major principal stress: (a) the major principal stress direction is coincident with direction $A\left(\alpha=0^{\circ}\right)$, and (b) the major principal stress direction is coincident with the direction of displacement of the sliding layer $\left(\alpha=\alpha_{\mathrm{av}}\right)$. The latter is described by averaging with depth of the direction of displacement of the sliding layer, calculated using existing conventional inclinometer measurements

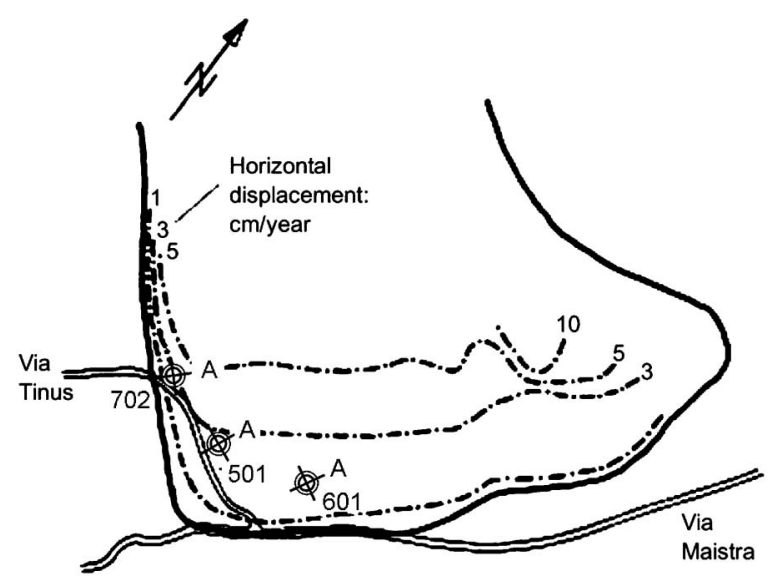

Fig. 17. Location and orientation of the measured inclinometers in the Brattas landslide in St. Moritz
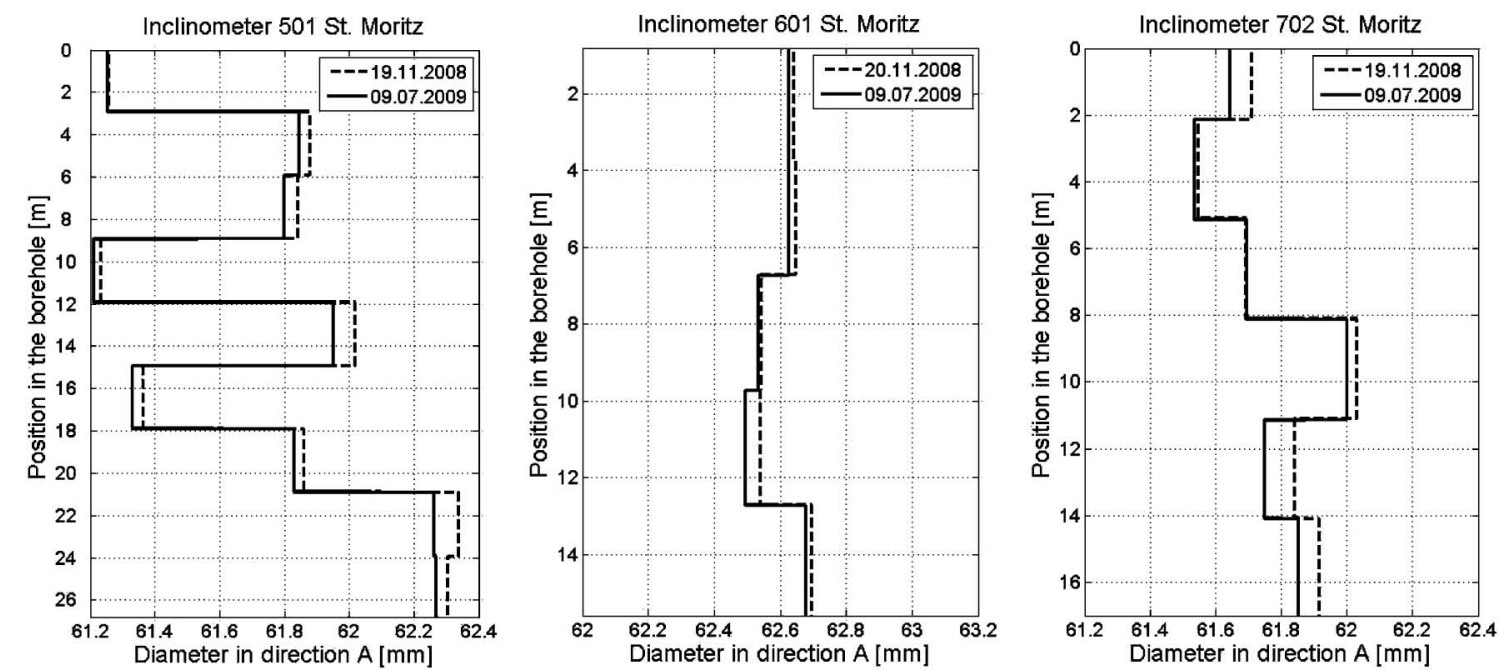

Fig. 18. Initial measurements of the sheared inclinometer pipe diameters in direction A in the compression zone of the St. Moritz landslide 
Table 1. Increase in pressure in principle direction in the compression zone of the St. Moritz landslide

\begin{tabular}{c|c|c|c|c|c}
\hline $\begin{array}{c}\text { Borehole } \\
\text { Nr. }\end{array}$ & $\begin{array}{c}\Delta D_{\mathrm{A}} \\
{[\mathrm{mm}]}\end{array}$ & $\begin{array}{c}\alpha_{\mathrm{av}} \\
{\left[{ }^{\circ}\right]}\end{array}$ & $\begin{array}{c}\Delta \alpha_{1} \\
\alpha=0^{\circ} \\
{[\mathrm{kPa}]}\end{array}$ & $\begin{array}{c}\Delta \alpha_{1} \\
\alpha=\alpha_{\mathrm{av}} \\
{[\mathrm{kPa}]}\end{array}$ & $\begin{array}{c}\Delta=\alpha_{1} \\
\alpha=\alpha_{\mathrm{av}} \\
\text { creep } \\
\text { corrected } \\
{[\mathrm{kPa}]}\end{array}$ \\
\hline 501 & -0.038 & 19.2 & 8.0 & 10.2 & 8.1 \\
601 & -0.022 & 17.1 & 4.6 & 5.5 & 4.4 \\
702 & -0.043 & 28.8 & 9.1 & 16.7 & 13.3 \\
\hline
\end{tabular}

taken prior to the shearing of the inclinometer pipe. In the direction of the minor principal stress, the plane strain assumption of a large landslide was made with kinematically constrained boundary conditions. The constitutive relations in the model are linear elastic. The Young's modulus and Poisson's ratio of the pipe are 2850 $\mathrm{MPa}$ and 0.3 , respectively. The grout around the inclinometer pipe is assumed to have the same stiffness as the surrounding soil. The soil behavior in loading is described by a Young's modulus of $6.7 \mathrm{MPa}$ and a Poisson's ratio of 0.25 defined from a combination of Cambridge and Marchetti dilatometer tests (Puzrin et al., 2008). For this value of the soil stiffness, the resolution of the device becomes $0.64 \mathrm{kPa}$. The increase in pressure in the observed period is shown in Table 1 and is significantly larger than the resolution of the measurements for both assumptions $\alpha=0^{\circ}$ and $\alpha=\alpha_{\mathrm{av}}$, even when considering, based on section Creep of the Inclinometer Pipe, that about $25 \%$ of the displacement has been caused by the creep of the pipe material.

This consistent non-negligible increase of pressure in the compression zone over a period of less than eight months implies that Brattas landslide in St. Moritz has to be analyzed considering the "potential failure scenario".

\section{FURTHER LANDSLIDE APPLICATIONS}

The IDM was applied to several other landslides in Switzerland with different boundary conditions and sliding behaviour from the Brattas Landslide, among them the Braunwald, Ganter and Laret landslides, all briefly introduced below.

The village of Braunwald is built on an unconstrained creeping landslide. This creeping landslide is notable in its free pressure boundary condition at the bottom part of the landslide since the village is located on a natural terrace. The change in the earth pressure in time will be measured in different cross-sections using IDM to confirm existence of compression and extension zones and to backcalculate the soil stiffness and shear strength.

The Ganter Bridge is built on an active creeping landslide with unknown boundary conditions at the bottom part. Some of its piers are founded in a creeping area within large caissons. At the bottom part of the creeping landslide, there is a riverbed which provides a boundary. The most important parameter-the change in the earth pressure in time at the bottom part-will be measured us- ing the inclinodeformometer.

The Laret landslide in St Moritz was discovered in 2008. The hypothesis is that this is a dormant landslide sporadically reactivated by construction in the area. When reactivated, it causes devastating damage to property. Earth pressure measurements taken by IDM will provide information to verify this hypothesis.

\section{CONCLUSIONS}

Research on the novel inclinodeformometer device is in its preliminary stages. Nevertheless, it looks promising due to simplicity and the accuracy of its measurements. In addition, it does not require any additional infrastructure other than standard inclinometer pipes, which are regularly installed anyway to monitor landslides. Furthermore, these pipes can be used for pressure change measurements in the sliding layer long after they were sheared along the slip surface and became unsuitable for inclinometer measurements. The backcalculation of pressures is a challenging task, requiring additional attention to be given to such effects as the viscosity of the pipe material, the stiffness of the grout and the non-linearity of soil behavior. Nevertheless, full scale laboratory tests performed in a $2 \mathrm{~m}$ high calibration chamber demonstrated that simple constitutive models can be used for making a backcalculation as a first approximation. Initial measurements in the Brattas Landslide in St. Moritz confirmed the existence of a compression zone and give an order of magnitude for the pressure increase in time, confirming a decrease in the shear strength on the sliding surface. This implies that Brattas landslide in St. Moritz has to be analyzed considering the "potential failure scenario".

\section{ACKNOWLEDGMENTS}

The work has been partially supported by the ASTRA/VSS grant VSS 2005/502 "Landslide-Road-Interaction".

\section{REFERENCES}

1) Bouma, A. L. (1993): Mechanik Schlanker Tragwerke. Ausgewählte Beispiele in der Praxis. Springer Verlag, Berlin.

2) Puzrin, A. M., Messerklinger, S. and Schmid, A. (2008): The in-situ stiffness of the sliding layer in a creeping landslide. Proc. 4th Int. Symp. on Deformation Characteristics of Geomaterials, Atlanta 1, 407-412.

3) Puzrin, A. M. and Sterba, I. (2006): Inverse long-term stability analysis of a constrained landslide. Géotechnique, 56, 483-489.

4) Schluechter, Ch. (1988): Instabilities in the area of St Moritz, Switzerland: geology, chronology, geotechnology. Proc. 5th Int. Symp. on Landslides, Lausanne 1, 1375-1380.

5) Schwager, M. V., Schmid, A. M. and Puzrin, A. M. (2009): Inclinodeformometer: A novel device for measuring earth pressure in creeping landslides. Proc. Int. Symp. on Prediction and Simulation Methods for Geohazard Mitigation, Kyoto, 479-484.

6) Sterba, I., Lang, H.-J. and Amann, P. (2000): The Brattas landslide in St Moritz. Proc. Int. Conf. Geotechnical and Geological Engineering: GeoEng 2000, Melbourne 2, 144. 